\title{
FDA's new plan to reduce the nicotine in cigarettes to sub-addictive levels could be a game-changer
}

\author{
Robert N Proctor
}

On 28 July 2017, US Food and Drug Administration (FDA) Chief Scott Gottlieb, MD, announced a bold new plan to limit the nicotine allowed in manufactured cigarettes. ${ }^{1}$ Gottlieb, a Trump appointee revealing C Everett Koop-like potential, pointed out that cigarettes remain the leading preventable cause of death in the USA, killing nearly half a million Americans every year. ${ }^{2}$ But of course it is the nicotine in cigarettes-kept above some crucial level and potencythat keeps people smoking and ultimately leads to disease, death and the suffering of families. Gottlieb did not specify a level below which nicotine would have to be lowered, but he did say it would have to render cigarettes 'minimally or non-addictive'.

Gottlieb's announcement caused a panic on Wall Street, where cigarette stocks took a plunge not seen for decades. Altria's market value was briefly down nearly $20 \%$, and other cigarette makers suffered significant losses. Altogether $\$ 60$ billion in market capitalisation was lost within an hour of the announcement-although part of that has been recovered in subsequent trading days.

A panic of this sort should not be surprising, given what is at stake. Cigarette sales are still an astronomical 6 trillion sticks per year, with steady declines in richer parts of the globe being balanced by rises elsewhere. And cigarette making is still remarkably profitable. Even after last month's losses, stock prices of the leading manufacturers remain near historic highs.

Cigarette manufacturing in fact remains among the most lucrative business enterprises in all of human history. Credit Suisse recently reported that tobacco provided by far the leading return on investment across all industries. A dollar invested in tobacco stocks in 1900 was worth an astonishing $\$ 6$ million by 2010 . $^{3}$ And cigarette stocks have continued to rise ever since-until last week.

The FDA's plan poses a threat to business as usual for cigarette manufacturers,

Correspondence to Dr Robert N Proctor, Department of History, Stanford University, Bldg 200, Stanford, California 94305, USA; rproctor@stanford.edu who have long considered themselves to be in the nicotine delivery business. As early as 1963 Addison Yeaman, Brown \& Williamson's powerful lawyer, wrote confidentially about British American Tobacco (BAT)'s efforts to make cigarettes that would retain the addictive potency of cigarettes, while dispensing with their 'unattractive side effects', meaning cancer and heart disease: 'we are, then, in the business of selling nicotine, an addictive drug effective in the release of stress'.

Gottlieb's plan follows an interestingly opposite logic. The new proposal is that cigarette makers should be barred from making cigarettes that addict their usersrecognising that it is the addiction that keeps smokers smoking, even when they would rather not. Gottlieb noted as 'Fact One' that 'the overwhelming amount of the death and disease attributable to tobacco is caused by addiction to cigarettes. 5

Crucial here is the idea of reducing the nicotine in the rod. By law the FDA is barred from reducing the nicotine to zero, but nothing prevents the agency from reducing it by, say, $95 \%$ or even $99 \%$. That is not technically difficult; the techniques most commonly used are similar to those used in decaffeinating coffee. Using these and other methods, Philip Morris itself in the 1980s and 1990s sold three different brands from which $97 \%$ of the nicotine had been eliminated. Those cigarettes did not contain sufficient nicotine to create and sustain addiction. The FDA will presumably establish some as-yet-undetermined ceiling for the nicotine in cigarettes, measured in terms of a maximum allowable percentage (by weight) of the alkaloid.

This 'nic-max' proposal differs radically from what used to be known as 'low tar' or 'light' cigarettes-marketing gimmicks now barred by law. Those cigarettes were advertised as delivering less tar and nicotine into the lungs, when in fact there was no reduction. 'Light' and 'low tar' cigarettes-like nearly all other cigarettes-were typically kept between $1 \%$ and $2 \%$ nicotine by weight, with the 'low nicotine' boast achieved either just by putting less tobacco in the rod or by attaching 'filters' pierced with microscopic holes that would 'ventilate' (ie, dilute) the smoke. When measured on smoking robots, which puffed according to a standardised protocol, such cigarettes did deliver less tar and nicotine. But these machines did not smoke like peoplebecause robots cannot be addicted and do not have lips. Human smokers 'titrated' their intake of nicotine by taking bigger puffs, or holding the smoke longer in their lungs, or smoking further down on the cigarette, or by covering the ventilation holes. Or by smoking more cigarettes.

The FDA's proposal is entirely different. Cigarette makers today keep the nicotine at $1 \%-2 \%$ by weight, having found this to be the sweet spot for creating smoker 'satisfaction' (one of several industry code words for nicotine addiction). Reducing this percentage by a factor of ten-to $0.1 \%$ or $0.2 \%$ - would make it very difficult for cigarettes to create or sustain addiction. Reducing it even further would make addiction virtually impossible.

This would essentially eliminate the cigarette as an engine of addiction, while preserving many of the other reasons people smoke-to ponder the wafting of the fumes, for example, or to obtain some form of oral gratification. Or to emulate Johnny Depp or Keira Knightley. Smokers would be able to start or quit at will, without suffering the robbery of choice that defines addiction.

Of course there are numerous ifs, ands and buts to such a proposal, and much in the way of details remains to be hammered out. For example, the approach is based on a presumption that addiction is primarily a physiological phenomenon, but research shows addiction also has psychological, physical and social elements. The industry could attempt to manipulate the product in ways that enhance absorption of the remaining nicotine, or change levels of nicotine analogues the products may already contain. Such changes would have to be submitted to the FDA for approval, however, making it harder for the industry to game the regulation.

Politically, tobacco companies will raise the spectre of prohibition, claiming that a dramatic reduction in nicotine will amount to a de facto ban on cigarettes. Or that reducing nicotine will create a Bonnie and Clyde-style crime wave, with smokers turning to speakeasies to obtain their high-nic fixes. Crucial here, though, will be the continued availability of numerous other legal means by which smokers will be able to acquire nicotine-nicotine patches, gums, inhalers and lozenges of course, but also the wide variety of vaping devices still on the market. 
Another question is how and whether other combustibles will be includednotably cigars, which are vexed by suffering the defect of combustion, but not necessarily the defect of inhalation, another crucial cause of cigarette harm. From a public health point of view, many of the cheaper cigars now being sold are really just big brown cigarettes-designed to be inhaled. The whole question of whether traditional premium cigars should be exempt from regulation remains an open one. Critics may also wonder about the delay in regulating e-cigarettes and vaping products, which have their own peculiarities when it comes to potential harm.

Another red flag is the nightmare of procedural delays and legal obstruction. The FDA's new proposal is described as the beginning of 'a multi-year plan', which does not bode well for the urgency this calamity deserves. Delay works to the advantage of Big Tobacco. The decadelong conspiracy that continues even today in certain respects was privately described in the industry's own documents as a 'holding strategy'. ${ }^{6}$ For decades the companies have known that while cigarettes are ultimately a lost cause, every year they can delay the inevitable is billions more in profits and those 'unattractive side effects' they have been so willing to tolerate.

Overall, though, this new FDA plan is certainly a breath of fresh air. If carried through with courage and conviction, it could save more lives than any other act of a governmental agency in all of human history. The magnitude of the harms is that great. We hear a lot about tobacco endgames: this one could be a game-changer.

Competing interests The author has served as an expert witness for plaintiffs in cigarette litigation.

Provenance and peer review Not commissioned; internally peer reviewed.

(C) Article author(s) (or their employer(s) unless otherwise stated in the text of the article) 2017. All rights reserved. No commercial use is permitted unless otherwise expressly granted.

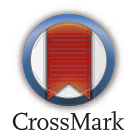

To cite Proctor RN. Tob Control 2017;26:487-488.

Tob Control 2017;26:487-488.

doi:10.1136/tobaccocontrol-2017-053978

\section{REFERENCES}

1 U.S Food \& Drug Administration. FDA News Release: FDA announces comprehensive regulatory plan to shift trajectory of tobacco-related disease, death. 2017 https://www.fda.gov/NewsEvents/Newsroom/ PressAnnouncements/ucm568923.htm

2 U.S Food \& Drug Administration. Protecting American Families: Comprehensive Approach to Nicotine and Tobacco. 2017 https://www.fda.gov/NewsEvents/ Speeches/ucm569024.htm

3 Dimson E, Marsh P, Staunton M. London Business School. Industries: their rise and fall. In: Credit suisse global investment returns yearbook, 2015:5-15. http:// publications.credit-suisse.com/tasks/render/file/index. cfm?fileid=AE924F44-E396-A4E5-11E63B09CFE37CCB

4 Yeaman A. Implications of Battelle Hippo / \& /I and the Grifffith filter: UCSF Brown \& Williamson, 1963. http:// legacy.library.ucsf.edu/tid/xrc72d00

5 U.S Food \& Drug Administration. Protecting American families: comprehensive approach to nicotine and tobacco. 2017 https://www.fda.gov/NewsEvents/ Speeches/ucm569024.htm

6 Panzer F. The Roper proposal. 1972 http://legacy.library. ucsf.edu/tid/whz50e00 